\title{
Processos criativos de avaliação em modelos ecológicos na pedagogia do esporte: construindo caminhos para a investigação e a intervenção
}

\section{Creative processes of evaluation of ecological models in sport pedagogy: building paths for research and intervention}

DOI: $10.46814 /$ lajdv3n3-039

Recebimento dos originais: 01/052021

Aceitação para publicação: 31/06/2021

\author{
Renato Sampaio Sadi \\ Doutor em Educação - PUC-SP \\ Universidade Federal de São João del Rei \\ E-mail: renatosampaio63@gmail.com
}

\section{RESUMO}

Processos criativos são questões estratégicas que dependem de variáveis externas (ambiente, equipamentos, materiais pedagógicos, planejamento e aplicação de jogos) e internas (pensamento de professores/treinadores, alunos/jogadores em constante interação social). Neste trabalho, os processos criativos de avaliação em modelos ecológicos foram explorados, a partir da perspectiva unitária de investigação e intervenção na pedagogia do esporte. Categorias e níveis de jogos foram problematizados. Questões sobre avaliação foram produzidas. O nível de complexidade do jogo foi cotejado com as perguntas hipotéticas aos jogadores. A metodologia aplicada foi qualitativa, descritiva e discursiva. Os resultados indicam um vasto terreno produtivo para a pedagogia do esporte, especificamente, a partir dos modelos do TGfU (Teaching Games for Understanding (e de sua variante TG - Tactical Games) e do novo Game Sense.

Palavras-chave: pedagogia do esporte, avaliação, criatividade.

\begin{abstract}
Creative processes are strategic issues that depend on external variables (environment, equipment, teaching materials, planning and application of games) and internal (thinking of teachers/coaches, students/players in constant social interaction). In this work, the creative processes of evaluation of ecological models were explored, from the unitary perspective of investigation and intervention. Game categories and levels were problematic. Questions about evaluation were produced. The game's level of complexity was collated with hypothetical questions to players. The methodology applied was qualitative, descriptive and discursive. The results indicate a vast productive terrain for sport pedagogy, specifically, from the TGfU (Teaching Games for Understanding (and its TG - Tactical Games) and the new Game Sense models)
\end{abstract}

Keywords: sport pedagogy, evaluation, creativity.

\section{INTRODUÇÃO}

Entre as inúmeras propostas e formulações na pedagogia do esporte, os modelos ecológicos, baseados em concepção por sistemas e dinâmica sistêmica e flexível de lógicas inerentes às diversas totalidades, como formação, experiência, intervenção e impactos externos, parecem atrativos para 
muitos docentes e discentes. Nestes modelos encontramos planejamentos e caminhos curriculares estruturados por categorias de jogos, a saber: jogos de invasão, jogos de rede/parede, jogos de rebatida/campo e jogos de alvo. Outras 5 categorias (Tempo, Espaço, Risco, Tática e Técnica) se destinam à avaliação do processo de ensino-aprendizagem do jogo, destacando perguntas e respostas direcionadas à uma plataforma avaliativa dos ambientes de ensino e treino, passível de ser mensurada. A possibilidade de compreender o jogo para jogar melhor é o ponto de partida dos modelos ecológicos da atualidade, sendo que não basta compreender para melhorar. É preciso adentrar nas questões das habilidades de movimento individual, das habilidades técnicas, táticas e estratégicas. Juntamente com este conjunto compreensivo, reside a questão da criatividade. A esta se soma a questão da competitividade e das engrenagens cooperação e corresponsabilidade. (Sadi, 2010). Pensar e verbalizar são, portanto, processos criativos que podem ser manifestados no jogo, mas que, muitas vezes dependem de conhecimento anterior assim como de variáveis externas (ambiente, equipamentos, materiais pedagógicos, planejamentos e aplicação de jogos e internas (pensamento de professores/treinadores, alunos/jogadores em constante interação social. O problema deste estudo é aproximar os processos criativos utilizando os jogos como meio de ensino e treino, dentro dos quais retiramos perguntas a serem ofertadas aos alunos/jogadores. Esta lógica advém da unidade açãocognição e de seus componentes centrais, a percepção, a atenção, a antecipação, a memória e suas fases (sensorial, curto prazo e longo prazo), o pensamento, a inteligência e a tomada de decisão (Matias \& Grecco, 2010). A pesquisa foi baseada no modelo do Teaching Games for Understanding (TGfU) na vertente específica do Tactical Games (TG) preconizada por Mitchell; Oslin; Griffin (2003) em conjunção com o modelo do novo Game Sense, de Breed \& Spittle (2020). Após revisão da literatura e das características dos modelos, esboçamos uma plataforma avaliativa específica composta por um planejamento de jogos, nos quais extraímos 30 questões, em forma de verificações sobre a compreensão do jogo.

\section{DESENVOLVIMENTO}

Descortinar a caixa preta de aulas e treinos passa por elencar as principais características dos modelos citados, observando suas congruências e seus limites. O TGfU é um modelo inglês de ensino esportivo da Educação Física para a escola e o clube; concebe o esporte coletivo em categorias de jogos, sendo o aluno o centro do processo (ênfase construtivista). Modifica jogos e cria representações em cenários de jogos considerados exagerados. Desenvolve os jogos reduzidos, com a distinção entre jogo e tarefa, para solidificar as questões táticas e técnicas do processo de compreensão; quando relacionado à crianças e jovens, respectivamente ao ensino de táticas, desenvolve uma variação 
denominada Tactical Games (Sadi, 2016). Em todas as formas deste modelo, existe a necessidade de criar questionamentos (perguntas e respostas planejadas) exigindo dos alunos/jogadores o pensamento sobre o jogo. O novo Game Sense é um modelo australiano de ensino esportivo da Educação Física para a escola e o clube; incorpora os os modelos táticos envolvendo a questão técnica no conjunto de habilidades fundamentais de movimento que, ao longo do processo educativo se tornarão habilidades esportivas específicas. Este modelo trabalha com o foco em objetivos e resultados esperados da aprendizagem. As questões táticas ganham relevo e são complexificadas com questões estratégicas do jogo. O tratamento das questões técnicas é sempre dentro do jogo. Um esquema simples representado por jogo, questionamentos, repetição do jogo e modificação se junta com a perspectiva de formação integral, afetiva e de comportamentos.

De posse deste conhecimento básico dos modelos e de um filtro democrático para o enquadramento às possibilidades de aplicação na realidade, esboçamos na presente investigação, a liberdade de criar as múltiplas perguntas que podem surgir no processo de ensino-aprendizagem dos jogos. Como método de pesquisa qualitativa utilizamos a ferramenta de Van Zanten (1994) que trata do acúmulo teórico-metodológico, o que pressupõe que a densidade teórica faça uma junção com as possibilidades de aplicação prática. Nesse sentido lançamos os aportes teóricos do TGfU em orientação às determinações de ensino, compreensão e criatividade no jogo (Griffin; Mitchell; Oslin, 1997; Butler; Griffin, 2010) somados às recentes apropriações do novo modelo do Game Sense (Breed \& Spittle, 2020). Os procedimentos técnicos foram organizados em três etapas: A -Seleção e descrição de jogos; B -Manipulação e adequação do conteúdo e da forma de cada jogo; C -Construção de plataforma avaliativa a partir das lógicas cognitivas que inclui os determinantes da memória sobre a ação.

O lastro teórico-metodológico desenvolvido ao longo dos anos permitiu situar os modelos dentro do espectro socioconstrutivista elou interacionista, uma ampla avenida de tensões. Ao tomar a decisão de ensinar, aprender, treinar, exercitar e render, professores e jovens são confrontados com o enigma da competitividade e do ceticismo e chamados a transpor obstáculos. Produzir e se divertir passa a ser o substrato das atividades. O jogo continua como meio de ensinar e aprender as bases do esporte e é somado à competição dentro e fora de aulas e treinos, como momento de fortalecimento, confiança e superação, ou seja, o jogo continua a ser uma poderosa ferramenta do processo. Nesta base formativa são incluídos os insumos do fazer do esporte: os exercícios e tarefas relacionados à técnica; os esquemas intelectivos das táticas; as dicas e leituras dentro das práticas; as perguntas e respostas do feedback avaliativo (Sadi, 2016). Há que se considerar também que, dentro das atividades, o jogo pode ser dividido, multiplicado e incentivado em variações e modificações. Os conceitos de desenvolvimento real e potencial, preconizados por Vygotsky, fundam a zona de desenvolvimento proximal sendo provável que esta esfera de desenvolvimento possa ser atingida por meio de intenso e 
contínuo esforço didático. Para a educação esportiva o desenvolvimento mais elevado possível também torna esta zona enigmática: nunca se sabe ao certo se estamos dentro ou fora dela. As atuações educacionais no esporte podem tornar este conceito ativo e dinâmico, no cotidiano de aulas e treinos, ou seja, pode-se visar um equilíbrio que rejeite os extremos, do fácil ao difícil, tornando o encontro excitante e passível de superação. Parado ou em movimento; falando ou em silêncio, a linguagem, os sinais comunicativos e o sistema visual formam uma complexa teia conceitual das funções psicológicas (Clara, 2017) Vale ressaltar que os fundamentos marxianos, ainda que insuficientes para a confrontação da atual realidade, edificam uma concepção de homem e de sociedade coadunadas com os pressupostos de Vygotsky. Trabalho, unidade, contradição, individualidade, classe social e intencionalidade são conceitos direta e indiretamente ligados à pedagogia do esporte. O processo de ensino-aprendizagem, portanto, deve ser orientado para além do nível de desenvolvimento real dos estudantes, ou seja, se situar no limite das zonas de desenvolvimento próximas aos desafios que estão postos às mentes em formação. Isso poderá contribuir para mudanças nas formas de ver e agir no mundo, isto é, para mudanças de intencionalidade, ancoradas por objetivos em perspectiva. O pensamento se torna mais profundo, mais rico, mais complexo.

\section{A. SELEÇÃO E DESCRIÇÃO DE JOGOS}

A assimilação de jogos obedece à 4 níveis de complexidade nas faixas etárias da educação básica, sendo o nível 1 = 9/10 anos; o nível 2 = 11/12 anos; o nível 3 = 13/14 anos e o nível 4 = 15/17 anos de idade (Sadi, 2010). Semelhanças, diferenças e pertinências entre formas de jogos e processos de ensino e treino implicam em focos de compreensão/aplicação de conhecimentos e ajustes nas faixas etárias. Assim, para descrever cada jogo é preciso situar seu sentido e significado, ou seja, enquadrar seu foco ao objetivo da aula ou sessão, orientando-se pelas condições cognitivas e motoras do grupo. Para cada nível, a formulação de perguntas obedece à lógica do jogo possível que inicia no mais fácil e se incrementa no mais difícil. Não se trata, portanto, de pré estabelecer idades e padrões, mas apenas mapear possibilidades. Também é importante frisar que jogos de níveis iniciantes (nível 1 e 2) podem ser aproveitados nos níveis mais elevados (níveis 3 e 4), sendo que o inverso não é verdadeiro. Na sequência, são descritos 8 jogos, sendo possível flexibilizar suas regras de acordo com o nível das turmas.

Jogo 1 = Bobinho 2x1. Dois jogadores atacantes começam com a bola e mantêm a bola longe do defensor ao correr ou passar. Não é permitido contato. Trocar o defensor a cada 15 segundos ou quando ele conseguir a posse da bola. Jogo $2=4$ Atacantes. 3 atacantes começam um em cada cone. Um cone começa sem ninguém. Um defensor começa no meio do quadrado. O objetivo dos três atacantes é manter a bola longe do defensor, que vai tentar cortar o passe. Os atacantes não podem 
passar a bola diagonalmente (pelo centro do quadrado). A cada passe, um atacante deve correr para o cone vazio, deixando apenas duas opções de passe. Os atacantes passam a bola na direção do cone, não entre eles. Depende do atacante que estiver correndo alcançar o cone e receber o passe. Tempo máximo de 20 segundos para alcançar o objetivo. Inverter as posições. Jogo $3=$ Quatro atacantes são espalhados em um quadrado de 10x10 metros. Dentro do quadrado deve haver um atacante contra um defensor. Qualquer atacante pode se mover desde que não esteja com a bola. $\mathrm{O}$ atacante não pode passar a bola para o lado oposto do quadrado. O objetivo dos atacantes é passar a bola por fora até que haja oportunidade de passar para o atacante dentro do quadrado. Para isso, devem passar a bola pelo menos três vezes do lado de fora. Após o atacante receber a bola, deve passar para outro atacante (sem que seja o mesmo que passou a ele) para marcar 1 ponto. O defensor que tocar na bola a qualquer momento marca 3 pontos. Variação: realizar quantos passes para dentro e para fora do quadrado for possível em 30 segundos. Inverter as funções. Jogo 4 = O Desafio. O jogo inicia com dois atacantes atrás da linha de partida. Em pares, os atacantes objetivam levar a bola até a linha de fundo sem que o defensor toque na bola. Não é permitido contato. Os atacantes podem correr com a bola ou passar. Cada defensor deve ficar dentro da sua linha (apenas movimentação lateral). São 4 linhas defensivas. Cada linha defensiva tem aproximadamente 10 metros de largura e é separada em cinco metros. Jogo $5=$ Pega-pega com bola. Este jogo pode ser desenvolvido em $4 \times 4$, $5 \times 5$ ou $6 \times 6$. A área de jogo é um quadrado de $15 \times 15$ metros. Uma equipe inicia com a bola e passa entre eles. Os jogadores não podem correr com a bola e o contato não é permitido. Quem estiver com a posse da bola tem o objetivo de tocar o adversário com a bola (sem arremessar nele). Ele não pode tocar na mesma pessoa duas vezes seguidas. Cada toque vale 1 ponto. A equipe sem a bola tem 90 segundos para evitar ser pego. Troca-se a posse e o segundo time tenta vencer o primeiro. Jogo $6=$ Ping-pong 3 x 3 . Este jogo é semelhante ao Voleibol com pingo, porém, a altura da rede é igual ao Tênis. O saque deve ser efetuado com um pingo. A recepção é permitida após um pingo. O jogo segue com as regras do Voleibol. Não é possível bloquear. Jogo 7 = Ping-pong 3 x 3 com um levantador fixo. Este jogo é semelhante ao anterior, mas com o desafio da infiltração. As equipes escolhem quem será levantador. Todos devem passar por esta função. Jogo 8 = Voleibol 4 x 4. Em cada equipe, dois rapazes e duas moças. Não é permitida a ação de ataque (cortada) apenas o toque por cima. As equipes jogarão por tempo de 5 minutos.

Estes jogos não estão sequenciados em um planejamento para determinada série ou temporadas, tampouco são parte ou destaque de algum documento de orientação. Trata-se de um conteúdo acumulado ao longo dos anos que pode ser utilizado como reflexão, estudo ou pesquisa de estudantes, professores e treinadores. 


\section{B. MANIPULAÇÃO E ADEQUAÇÃO DO CONTEÚdO E DA FORMA DE CADA JOGO AOS NÍVEIS DE COMPLEXIDADE}

O universo do jogo e suas particularidades estão presentes a cada jogada realizada, ou seja, a imprevisibilidade, como uma constante temporal, poderá emergir e alterar o destino do jogo. Ao manipular e adequar o conteúdo e a forma de cada jogo costuramos possibilidades de observação, análise e criatividade. Tal engenharia permite tornar o jogo mais objetivo, visando seu controle. Entendemos, nesse sentido que cabe ao professor/treinador, atuar permanentemente com tais ferramentas operativas, isto é, com a manipulação e adequação dos jogos. Devemos levar em consideração algumas questões: qual é a velocidade da movimentação dos jogadores por meio de passes curtos e longos que são capazes de realizar. O passe, a finta, as diversas formas de deslocamento e aproveitamento no espaço, ocorrem em que medida? Diante de rápidos pensamentos como: Esse é o jogo possível do momento, é o jogo que os jogadores são capazes de apresentar, o professor/treinador propõe uma intervenção que deve ser orientada por dicas, incentivos e perguntas ao invés de instruções diretas e cobranças. Sabendo que a motivação atinge a cognição tornando-se uma ferramenta ativa da relação pensamento rápido - ação rápida, podemos imprimir dinamismo ao jogo, potencializando seu processo de ebulição criativa por parte dos jogadores. Isso implica na socialização entre os jogadores de informações sobre o posicionamento em quadra e troca de saberes relacionados à experiências pregressas questões dependentes da idade que podem ser absorvidas pelo jogo. Uma outra exigência bastante conflituosa para os jogadores iniciantes é a questão do passe, o quando passar e o como passar. Trata-se de uma ação difícil e, portanto, desafiadora para o processo ensino-aprendizagem. Em raras situações, os professores/treinadores atuam na construção de um pensamento complexo, se limitando a jogos fáceis e soltos. Esta é uma crítica cujo objetivo é melhorar o ensino, não o destruir. Alunos/jogadores parados e desinteressados precisam, obviamente serem observados e tratados por pedagogia de qualidade. De qualquer maneira, entendemos as dificuldades, razão pela qual indicamos a forma dos jogos, partindo do mais simples em direção ao mais complexo. Os 4 níveis de complexidade citados anteriormente, nesta lógica, seriam agrupados em 2 novos níveis: Nível iniciante $=$ dos 9 aos 12 anos; Nível de consolidação da iniciação = dos 13 aos 16 anos de idade. Neste ponto é preciso justificar tal enquadramento. Os níveis de complexidade dos jogos dependem dos níveis de complexidade de conhecimento dos jogadores. Assim, como temos uma importação dos modelos (do estrangeiro) os jogos e suas nuances, em nossa realidade, necessitam de adaptação na estrutura e na oferta às crianças e jovens. Para a realidade educacional de escolas e clubes o alargamento das idades possibilita aos alunos/jogadores mais velhos traduzirem os pormenores do jogo aos alunos/jogadores mais novos, embora saibamos que há diferenças latentes em maiores intervalos de idades. 


\section{C. CONSTRUÇÃO DE PLATAFORMA AVALIATIVA}

30 questões produzidas para avaliar a compreensão foram separadas e distribuídas entre os 8 jogos, tendo em vista a coerência, o nível da pergunta e a capacidade de resposta das crianças e jovens. Na sequência, apresentamos as questões que podem (e devem) ser desdobradas para que o debate seja promovido e reproduzido. As questões estão separadas em gerais (15) e específicas (15).

Questões gerais:

1. Quanto tempo demorou o jogo? 2. Podemos jogar mais rápido? 3. Quando você decidiu arremessar/chutar? 4. Qual foi o tempo médio de posse de bola de ambas as equipes? 5. Qual é o tamanho do espaço de dentro e de fora da quadra? 6. Para quem você passou a bola? 7.Qual é a melhor distância para sacar/arremessar/chutar? 8. Por onde é melhor atacar? Direita, centro ou meio? 9. Quais são os melhores jogadores do time adversário? 10. O que deve ser feito quando o time adversário pegar a bola? 11. O que deve ser feito para não juntar muita gente perto da bola? 12. Antes de sacar/atacar/chutar no que você pensa? 13. Quais as diferenças entre uma defesa aberta e uma defesa fechada? 14. Ao decidir passar a bola, você conseguiu fotografar mentalmente a posição dos jogadores? 15. Qual técnica você utilizou mais neste jogo?

Questões específicas:

1. Quando você estava com a posse da bola, optou por passar para a esquerda, direita ou tentar driblar? 2. No início do jogo é melhor estudar o adversário ou sair jogando e deixa-lo jogar? (qual será o tempo para isso?) 3. O que fazer ao escolher uma jogada que deu errado? 4. Em cada espaço dividido (defesa, meio, ataque) qual é o nome (função) dos jogadores? 5. O que você fez quando estava perdendo e faltava pouco para acabar? 6. O que deve ser feito quando o time adversário provocar e/ou fazer falta? 7. Quando ocorrer a perda da posse de bola o que fazer para recompor a equipe? 8. O que você fez quando arriscou o saque/arremesso/chute? Conseguiu visualizar o seu time? E o adversário? 9. Como conduzir a bola ao ataque sem ter medo de perde-la? 10. Como que você salta para arremessar/atacar? No momento destes saltos, como é a sua técnica? 11. Quando utilizou suas técnicas pensou em não fazer falta? 12. Como você vem melhorando suas técnicas? 13. Você consegue perceber as modificações nos jogos e o que estamos fazendo nas aulas/treinos? 14. Em um momento tenso do jogo, como você controla suas emoções? 15. Você é capaz de escrever sobre diferentes jogos e esportes, considerando as habilidades de movimento, técnicas, táticas e estratégicas? 


\section{CONCLUSÃO}

Em outra oportunidade, o diálogo sobre modelos ecológicos resultou em um amálgama de forças, dispostas a reproduzir e melhorar, de forma criativa, as bases do TGfU. Variantes como o Game Sense, o Tactical Approach, o Play Practice Approach, o Tactical Decision Making Approach foram condensados na perspectiva de um ensino de esporte por meio de jogos, a sustentação construtivista destes modelos (Mesquita, 2013). A especificidade do TG e seu ensino de táticas dentro de jogos reduzidos, permitiu o salto para as especificidades da avaliação processual, ou seja, as perguntas e respostas sobre o jogo (Sadi, 2018). Atualmente, o desdobramento dos modelos e suas peças avaliativas indicam que a variedade de perguntas e sua correta aplicação é questão prioritária em relação às possíveis respostas dos alunos/jogadores

O universo do jogo, ao se aproximar, cada vez mais, do mundo do esporte, edifica um jogador versátil para o futuro. Trata-se de um tema central que envolve o ensino-aprendizagem do esporte em torno dos processos criativos, abrindo um amplo leque de fertilizações. Este jogador versátil e ético é uma aposta para a pedagogia do esporte. Seu cérebro e coração serão decisivos no quadro de respostas ao jogo. Assim, a produção e reprodução de conhecimentos, pode ser explorada, a partir de modificações dos jogos, por meio de perguntas específicas e coerentes aos jogadores, de acordo com seu nível. As perguntas abertas ou gerais visam retomar o controle da memória, fixando padrões mentais que poderão ser acessados no futuro breve ou mesmo ao longo da vida esportiva. Por outro lado, as questões específicas visam reflexões inéditas que se traduzem em aprofundamento de conhecimentos. Os alunos/jogadores, quando estimulados à tais pensamentos poderão ativar centros mentais de criatividade e espalhar formas alternativas de resolução de problemas entre o grupo. Conclui-se, portanto que, as perguntas sobre a compreensão do jogo se revelam pertinentes, na medida em que as lógicas do jogo possam favorecê-las. Pensar sobre o jogo e verbalizar o conjunto de ações ambientais do jogo e dos jogadores conferem densidade e criatividade ao processo pedagógico. 


\section{REFERÊNCIAS}

BREED, R.; SPITTLE, M. Developing Game Sense in Physical Education and Sport. Human Kinetics, 2020.

BUTLER, J.; GRIFFIN, L. (orgs) More teaching games for understanding: moving globally. Human Kinetics, 2010.

CLARA, M. Como A Instrução Influencia O Desenvolvimento Conceitual: A Teoria De Vygotsky Revisitada. Revista Educativa-Revista de Educação, v. 20, n. 3, p. 659-690, 2017.

GRIFFIN, L.; MITCHELL, S. A; OSLIN, J. Teaching sport concepts and skills: A tactical games approach. Human Kinetics, 1997.

MATIAS, C. J.; GRECO, P. J. Cognição \& ação nos jogos esportivos coletivos. Ciências e cognição, v. 15, n. 1, p 252-271, 2010.

MESQUITA, Isabel. Perspectiva construtivista da aprendizagem do ensino do jogo. In: Nascimento, J. V.; Ramos, V; Tavares, F (orgs) Jogos desportivos: formação e investigação pp. 103-132. Universidade do Estado de Santa Catarina, 2013.

MITCHELL, S.; OSLIN, J.; GRIFFIN, L. Sport foundations for elementary Physical Education: A tactical games approach. Human Kinetics, 2003.

SADI, R. Pedagogia do Esporte: descobrindo novos caminhos. Ícone, 2010.

Pedagogia do Esporte: explorando os caminhos da formação permanente e da intervenção criativa em crianças e jovens esportistas. Ícone, 2016.

- A variante Tactical Games do modelo Teaching Games for Understanding no ensino e no treino do Voleibol: aplicações em cenários de jogos diversos, Academia, 2018.

VAN ZANTEN, A. Pesquisa qualitativa em educação: pertinência, validez, generalização. Perspectiva, 22, 25-45, 2004.

VYGOTSKI, L. A formação social da mente. Psicologia, v. 153, p. V631, 1989.

Pensamento e linguagem. 2008. 